\title{
Minority Health and Assistance, Targeted
}

National Cancer Institute

\section{Source}

National Cancer Institute. Minority Health and Assistance, Targeted. NCI Thesaurus.

Code C18879.

Health aid that is directed to minority groups. 